\title{
Genetic variation in the endemic and endangered Rosmarinus tomentosus Huber-Morath \& Maire (Labiatae) using RAPD markers
}

\author{
JUAN PEDRO MARTÍN†* \& J. ESTEBAN HERNÁNDEZ BERMEJO† \\ $\dagger$ Departamento de Biología Vegetal, Escuela Técnica Superior de Ingenieros Agrónomos, Universidad Politécnica \\ de Madrid, Ciudad Universitaria, 28040-Madrid, Spain, †Jardín Botánico de Córdoba (Departamento de Ciencias y \\ Recursos Agrícolas y Forestales), Universidad de Córdoba. Avda Linneo s/n, 14004-Córdoba, Spain
}

\begin{abstract}
Rosmarinus tomentosus Huber-Morath \& Maire, an endemic species of southern Spain, is critically endangered as a consequence of habitat destruction by anthropogenic activities. Random amplified polymorphic DNA (RAPD) markers were used for initial evaluation of genetic variation in this species; among zones, among populations (within zones and independently of zones), and among individuals (within populations and zones). The eight primers used to study five populations provided 126 reliable bands, of which 109 (86\%) were polymorphic. Analyses of the RAPD markers conducted using different approaches (cluster analysis, Shannon's diversity measure and analysis of molecular variance-AMOVA) showed similar results concerning genetic structure of populations of $R$. tomentosus. The three zones studied, and their corrresponding populations, were clearly defined through UPGMA analysis. AMOVA analyses indicated that $18.0 \%$ of the total genetic variation was attributable to differences among zones. When total variance was partitioned without considering the zonal distribution of the populations, $34.1 \%$ was attributable to differences among populations, and $65.9 \%$ to differences among individuals within populations. Similar results were obtained using Shannon's information measure. Significant genetic distances ( $\mathrm{Phi}_{\text {st }}$ values) were obtained between any two populations. This strong genetic differentiation among zones, populations and subpopulations may be explained by geographical distances and limited gene flow. This study will be of considerable help during subsequent formulations of conservation strategies for the endangered species $R$. tomentosus.
\end{abstract}

Keywords: conservation, endangered species, population genetic structure, RAPD, Rosmarinus tomentosus.

\section{Introduction}

Rosmarinus tomentosus Huber-Morath \& Maire is a Spanish endemic species found in a very small coastal region within the province of Granada and barely extending into the province of Málaga (both provinces in southern Spain). It is a diploid $(2 n=24)$ canescent, chasmophyte shrub with abundant branching, and has stems and small leaves covered with thick, greyish-white tomentum (Maire, 1940; Rosúa, 1981). This species is predominantly outcrossing, as are most species of Labiatae (Owens \& Ubera-Jiménez, 1992), with entomophilous pollination mainly by Hymenoptera, such as bees and bumblebees (J. E. Hernández Bermejo, pers.

*Correspondence. E-mail: jpmartin@bio.etsia.upm.es obs.). R. tomentosus plants grow on coastal cliffs at altitudes between 0 and $250 \mathrm{~m}$ a.s.1.; some of these cliffs have formed inland, as a result of fluvial sedimentation from the Guadalfeo river. According to recent estimates, fewer than 40000 individuals survive distributed in the three zones. (i) The western zone is made up of two coastal populations, CG (the cliffs of Cerro GordoCantarriján) has fewer than 20000 plants and PM (Punta de la Mona), separated from the first location, has between 400 and 500 plants. (ii) The central and interior zone has one population $(\mathrm{G})$ of about 300 individuals that grow in the Guadalfeo gorge, a former estuary that is now $10 \mathrm{~km}$ inland from the coast. (iii) The eastern zone, on the coast between localities of Calahonda-Punta Cerrón (C-PC) and Castell de Ferro- Punta Gorda (CF-PG), has no more than 15000 plants. These plants are well adapted to this hostile 
ecological niche, characterized by extreme sun exposure, scarce precipitation, strong winds and saline environment (Hernández Bermejo \& Clemente Muñoz, 1994).

Although the species is well adapted in nature, it is categorized as 'Endangered' (Hernández Bermejo \& Clemente Muñoz, 1994). This is principally a result of the anthropogenic pressure in its distribution area (e.g. tourism, housing developments, pollution, widening of highways), leading to its rapid demographic and geographical decline. Moreover, this species has serious reproductive limitations, both asexually (difficulties in rooting of cuttings) and sexually (scant flowering, low seed productivity, very low germination capacity and prolonged latency periods) (J.E. Hernández Bermejo, pers. obs.). Therefore, very few young plants are found in the wild. Another risk for the species is its propensity to hybridize with $R$. officinalis L. The hybrid, R. x mendizabalii Sagredo ex Rosúa (Rosúa, 1981, 1986), is especially frequent in the central and interior population in the Guadalfeo valley, although it is much less frequent in the eastern and western coastal populations, where the hostile climatic conditions put $R$. tomentosus at an advantage over $R$. officinalis and the hybrids. For all these reasons $R$. tomentosus should be re-evaluated as a 'Critically Endangered' taxon (IUCN, 1994).

Different DNA fingerprinting methods are useful tools with a wide range of applications in plant population studies, such as detection of genetic variation within and among populations, analysis of breeding systems, and studies of ecogeographical variation (Weising et al., 1995). The development of random amplified polymorphic DNA (RAPD) markers (Williams et al., 1990) has proved useful for initial assessment of genetic variation in population and ecological contexts (Hadrys et al., 1992; Gillies et al., 1997; Bussell, 1999). The RAPD procedure often yields large numbers of markers, it is technically simple to perform and does not need either large amounts of DNA or previous information of DNA sequences, which are often unknown in wild plants. The utilization of these markers in genetic diversity and population structure studies of plant species has increased in recent years (e.g. reviewed in Bussell, 1999), and especially for endemic, rare and/or endangered species, e.g. Grevillea scapigera (Rossetto et al., 1995), Erodium paularense (Martín et al., 1997), Caesalpinia echinata (Cardoso et al., 1998), and Cerastium fischerianum var. molle (Maki \& Horie, 1999).

Analysis of population genetic structure using RAPD markers can be carried out using different approaches. Shannon's diversity measure (King \& Schaal, 1989) and Analysis of Molecular Variance (AMOva; Excoffier et al., 1992) overcome some of the difficulties of the other methods, such as those given by Clark \& Lanigan (1993) and Lynch \& Milligan (1994), which have limitations in some of their assumptions (Bussell, 1999). The Shannon's information measure has been applied for obtaining a partition of genetic variability within and between populations using RAPD markers in several plant species (Martín et al., 1997; Wolff et al., 1997; Cardoso et al., 1998; Bussell, 1999). The AMOva program was designed for haploid data but it has been used successfully for RAPD data (Huff et al., 1993; Rossetto et al., 1995; Gillies et al., 1997; Martín et al., 1997; Cardoso et al., 1998). These reports have shown the strength of AMOVA as an analytical tool that serves to discern regional and population differences.

Accurate estimates of diversity are of great importance for formulating appropriate conservation and management strategies of the genetic resources of a species. Keeping this in view, in this paper we have assessed the genetic variation among zones, within and among populations of the endemic and endangered species Rosmarinus tomentosus using RAPD markers.

\section{Materials and methods}

\section{Plant material}

One hundred and ten individuals of Rosmarinus tomentosus (22 individuals in each of the five populations studied) were labelled in the field, and leaf material was collected for assessment of genetic variability. There were two coastal populations, which represented the eastern limit of the distribution area of the species: Castell de Ferro-Punta Gorda (CF-PG) and Calahonda-Punta del Cerrón (C-PC). Two other coastal populations, Punta de la Mona (PM) and Cerro Gordo (CG), represented the western limit. The last population (G) was located in a central zone, more interior towards the land where the Guadalfeo river reaches its final course, next to the edge of Motril (Granada) (Fig. 1, Table 1). In the populations CF-PG and G, the 22 individuals were sampled as two subpopulations (CF-PG I and II; GI and II) and were separated by a distance of $200 \mathrm{~m}$ and $500 \mathrm{~m}$, respectively. Individuals were sampled randomly and separated by at least 5-10 m.

\section{DNA extraction, amplification and electrophoresis}

DNA was extracted from frozen young leaves of single individuals following the protocol of Torres et al. (1993). Extracted DNA was quantified using a spectrophotometer, and also by comparing band intensities with known standards of lambda DNA on $1 \%(\mathrm{w} / \mathrm{v})$ agarose gels. Working solutions of DNA $\left(3 \mathrm{ng} \mu \mathrm{L}^{-1}\right)$ were made using sterile, double-distilled water. 


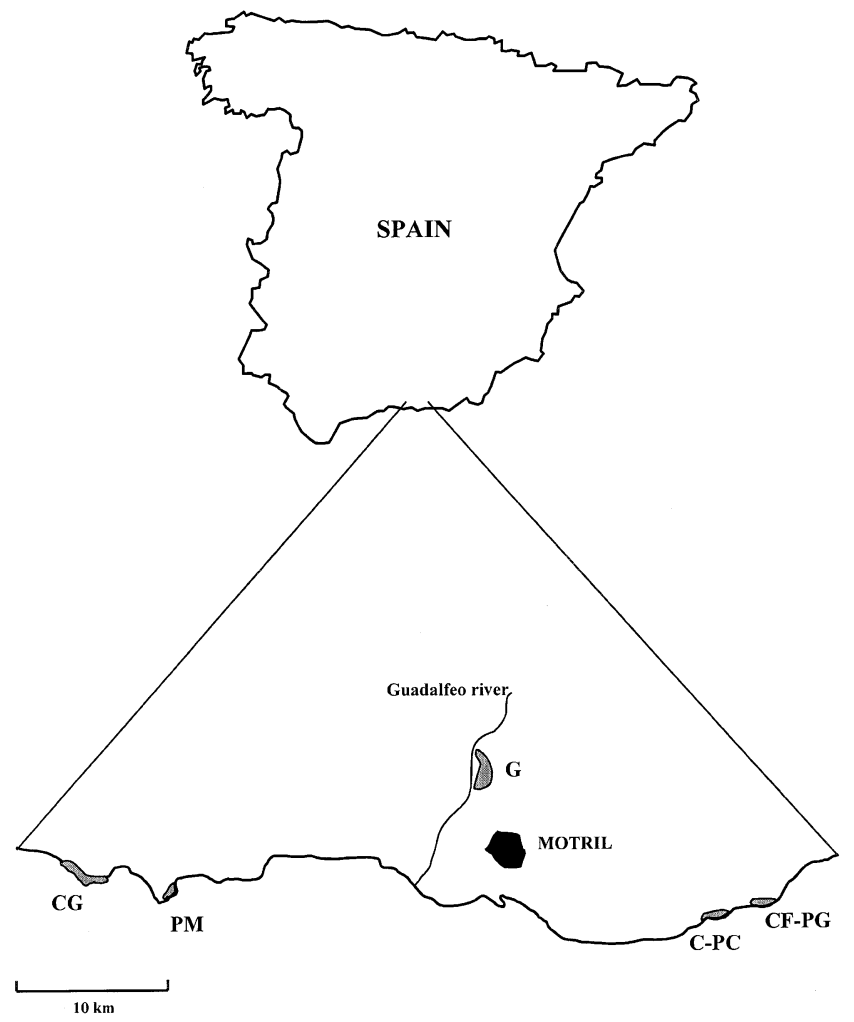

Fig. 1 Geographical location of the five populations of Rosmarinus tomentosus studied (CG, population of Cerro Gordo; PM, population of Punta de la Mona; G, population of Guadalfeo; C-PC, population of Calahonda-Punta del Cerrón; CF-PG, population of Castell de Ferro-Punta Gorda).

In a preliminary study, 20 decamer primers of arbitrary sequence ('Kit O' provided by Operon Technologies Inc., Alameda, CA) were tested for PCR amplification. Eight of these RAPD primers were chosen (based on number and polymorphism of amplified fragments) to analyse the genetic variability of the samples (Table 2). DNA amplifications were performed in a $20-\mu \mathrm{L}$ reaction volume containing about $30 \mathrm{ng}$ template DNA, $0.2 \mu \mathrm{m}$ of a single primer, $200 \mu \mathrm{m}$ of each dNTP and 1.5 units of BIOTAQ ${ }^{\mathrm{TM}}$ DNA polymerase in the buffer provided by the enzyme manufacturers
(Bioprobe systems). Amplification was performed in a PTC-100 thermal cycler (MJ Research, Inc.) with a heated lid, and programmed for an initial step of $2 \mathrm{~min}$ at $94^{\circ} \mathrm{C}$, followed by 35 cycles of $30 \mathrm{~s}$ at $94^{\circ} \mathrm{C}, 1 \mathrm{~min}$ at $37^{\circ} \mathrm{C}$ and 2 min at $72^{\circ} \mathrm{C}$, and finally a 5 minute extension at $72^{\circ} \mathrm{C}$.

The amplification products were separated on $1.5 \%$ $(\mathrm{w} / \mathrm{v})$ agarose gels, in $1 \times \mathrm{TBE}$ buffer, at $3 \mathrm{~V} \mathrm{~cm}^{-1}$ for $4 \mathrm{~h}$, and then stained with ethidium bromide $\left(0.5 \mu \mathrm{g} \mathrm{mL}^{-1}\right)$ for $12 \mathrm{~min}$. Gels with amplification fragments were visualized and photographed under UV light. Molecular weights were estimated by reference to a 100-bp ladder (Pharmacia). All the amplifications were repeated at least twice and only reproducible bands were considered for analysis.

\section{Data analysis}

The RAPD bands were scored as 1 (present) or 0 (absent). A matrix of similarities between every pair of individuals was created using the Dice's similarity index (Dice, 1945), $S=2 n_{x y} /\left(n_{x}+n_{y}\right)$, where $n_{x}$ and $n_{y}$ are the total number of fragments analysed in individuals $x$ and $y$, respectively, and $n_{x y}$ is the number of fragments shared by the two individuals. The similarity matrix was employed to construct a UPGMA dendrogram, using the SAHN-clustering and TREE programs from NTSYS-pc, v. 1.6 (Rohlf, 1992). A cophenetic matrix was derived from the similarity matrix to test goodness-of-fit of the clusters, by comparing the two matrices using the Mantel matrix correspondence test (Mantel, 1967) in the MXCOMP program of the NTSYs-pc package.

Genetic diversity was estimated using Shannon's information measure (King \& Schaal, 1989), $H_{\mathrm{o}}=$ $-\sum p_{i} \log _{2} p_{i}$, where $p_{i}$ is the frequency of a given RAPD fragment. $H_{\mathrm{o}}$ was calculated at two levels: the average diversity within populations $\left(H_{\mathrm{pop}}\right)$, and the total diversity $\left(H_{\mathrm{sp}}\right)$. Then the proportion of diversity within populations was estimated as $H_{\mathrm{pop}} / H_{\mathrm{sp}}$, and the proportion of diversity among populations as $\left(H_{\mathrm{sp}}-H_{\mathrm{pop}}\right) /$ $H_{\text {sp. }}$.

In addition, an analysis of molecular variance (AMOvA; Excoffier et al., 1992) was applied to estimate variance components for RAPD phenotypes, partitioning

Table 1 Code, sample size $(N)$ and location of each population of Rosmarinus tomentosus studied

\begin{tabular}{lllll}
\hline Population & \multicolumn{1}{c}{ Code } & \multicolumn{1}{c}{$N$} & \multicolumn{1}{c}{ Location } & Latitude, longitude, altitude \\
\hline Castell de Ferro-Punta Gorda & CF-PG (I, II) & $11+11$ & Eastern coastal cliff & $36^{\circ} 42^{\prime} 46^{\prime} \mathrm{N}, 3^{\circ} 22^{\prime} 32^{\prime} \mathrm{W}, 40-50 \mathrm{~m}$ \\
Calahonda-Punta del Cerrón & C-PC & 22 & Eastern coastal cliff & $36^{\circ} 42^{\prime} 17^{\prime} \mathrm{N}, 3^{\circ} 23^{\prime} 43^{\prime} \mathrm{W}, 20-30 \mathrm{~m}$ \\
Guadalfeo & G (I, II) & $10+12$ & Central zone & $36^{\circ} 47^{\prime} 17^{\prime} \mathrm{N}, 3^{\circ} 32^{\prime} 11^{\prime} \mathrm{W}, 200 \mathrm{~m}$ \\
Punta de la Mona & PM & 22 & Western coastal cliff & $36^{\circ} 43^{\prime} 15^{\prime} \mathrm{N}, 3^{\circ} 43^{\prime} 44^{\prime} \mathrm{W}, 10-20 \mathrm{~m}$ \\
Cerro Gordo & CG & 22 & Western coastal cliff & $36^{\circ} 44^{\prime} 19^{\prime} \mathrm{N}, 3^{\circ} 46^{\prime} 36^{\prime} \mathrm{W}, 10-20 \mathrm{~m}$ \\
\hline
\end{tabular}


Table 2 Characteristics of the RAPD markers generated using eight primers with 110 individuals of Rosmarinus tomentosus sampled from five populations

\begin{tabular}{lcrcc}
\hline $\begin{array}{l}\text { Primer } \\
\text { Code }\end{array}$ & $\begin{array}{c}\text { Nucleotide sequence } \\
5^{\prime} \text { to } 3^{\prime}\end{array}$ & $\begin{array}{c}\text { No. of polymorphic } \\
\text { markers }(\%)\end{array}$ & $\begin{array}{c}\text { Size range of } \\
\text { fragments (bp) }\end{array}$ \\
\hline OPO-01 & GGCACGTAAG & 20 & $(100)$ & $340-1080$ \\
OPO-02 & ACGTAGCGTC & 13 & $(100)$ & $280-830$ \\
OPO-03 & CTGTTGCTAC & 14 & $(87)$ & $400-1300$ \\
OPO-07 & CAGCACTGAC & 18 & $(90)$ & $270-1160$ \\
OPO-08 & CCTCCAGTGT & 8 & $(61)$ & $520-1450$ \\
OPO-15 & TGGCGTCCTT & 15 & $(83)$ & $490-2050$ \\
OPO-16 & TCGGCGGTTC & 14 & $(93)$ & $440-1200$ \\
OPO-19 & GGTGCACGTT & 7 & $(64)$ & $270-900$ \\
Total & & 109 & $(86)$ & $270-2050$ \\
\hline
\end{tabular}

the variation among zones, among populations (within zones and independently of zones), and among individuals (within populations and within zones). Separate analyses were carried out within eastern and western zones, and within CF-PG and G populations. For these analyses, the distance metric used was $D=100(1-S)$ for all pairs of individuals, where $S$ is Dice's estimator of similarity (Dice, 1945). Levels of significance of variance component estimates were computed by nonparametric permutational procedures (i.e. 2000 random permutations). Homogeneity of molecular variance among zones, populations and subpopulations were tested with Bartlett's statistics. Pairwise Phi $\mathrm{P}_{\text {st }}$ distances (analogous to $F$-statistics at the molecular level; Excoffier et al., 1992) were calculated among populations, and their significance were also tested by a permutation procedure, using 2000 permutations. All analyses were carried out using WINAMOVA v. 1.55, provided by Laurent Excoffier (Genetics and Biometry Laboratory, University of Geneva, Switzerland). A Mantel matrix correspondence test (Mantel, 1967) was used to analyse correlation between genetic ( $\mathrm{Phi}_{\mathrm{st}}$ values) and geographical distances among populations.

\section{Results}

\section{RAPD profile}

Of the 126 reliable bands analysed in the amplifications with the eight chosen primers, 109 bands $(86 \%)$ were polymorphic in the five populations (Table 2). Considering each population separately, 48 polymorphic markers $(58 \%)$ were found in population CF-PG, 72 $(72 \%)$ in population C-PC, $71(69 \%)$ in population G, $51(54 \%)$ in population PM, and $47(55 \%)$ in population CG. The eight primers revealed polymorphic bands, ranging between $61 \%$ (OPO-8) and 100\% (OPO-1 and OPO-2); and the size range of the analysed fragments varied between 270 and $2050 \mathrm{bp}$ (Table 2).
Ten individual-specific bands were observed in four populations: five individuals in population C-PC, two in population $G$, two in population $P M$, and one in population CG. Also, 14 population-specific bands were found. Nine of these bands were present in less than $20 \%$ of the individuals of the corresponding populations, four were represented in $20-40 \%$ of the individuals of the populations, and one unique band (OPO15-1500) was present exclusively in all the individuals of population C-PC (Fig. 2). Five additional bands that characterized the individuals of eastern and western zones were observed. Bands OPO8-700, OPO8-560 and OPO16-1200 were present in $35 \%$ to $90 \%$ of the individuals of the eastern (CF-PG, C-PC) and central (G) zones, but were absent in all individuals from the western (PM, CG) zone. Conversely, bands OPO7-1140 and OPO16-620 were present in $55 \%$ to $80 \%$ of the individuals of the western (PM, CG) and central $(\mathrm{G})$ zones, but were absent in all individuals from the eastern (CF-PG, C-PC) zone. Comparing all the populations, band OPO15-2050 was present in all the individuals of one population from each of the three zones: CF-PG (eastern zone), PM (western zone) and $G$ (central zone), and was absent from the populations C-PC and $\mathrm{CG}$, belonging to eastern and western zones, respectively (Fig. 2).

\section{Cluster analysis}

The UPGMA dendrogram obtained using the 126 RAPD markers scored in the 110 individuals showed five welldefined groups, which correspond to the five populations. Furthermore, population clusters corresponding to eastern zone, central zone and the western zone were also observed in the phenogram (Fig. 3).

The 22 individuals from each of populations CF-PG, $\mathrm{PM}$ and $\mathrm{CG}$ formed distinct clusters. In population C-PC, 20 out of 22 individuals formed a group, whilst the remaining two individuals were outside of this group 

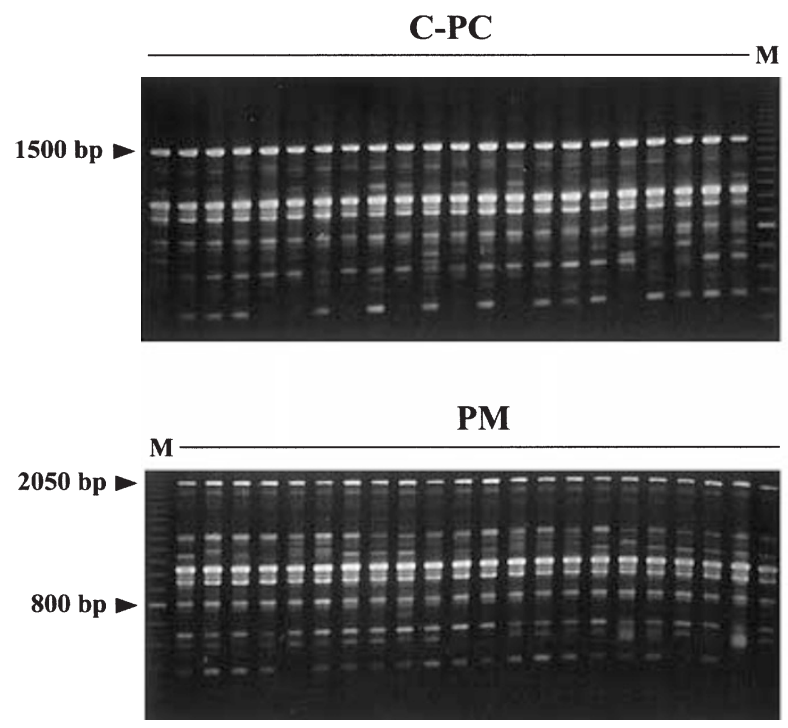

G I

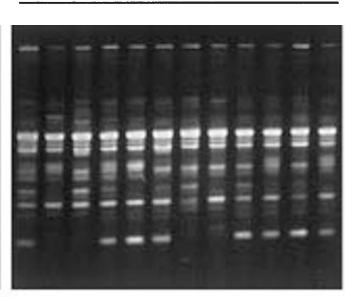

G II

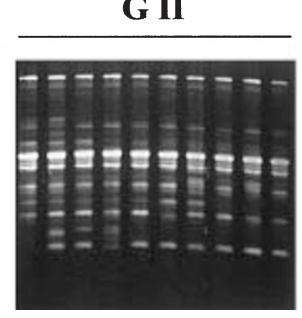

CF-PG I
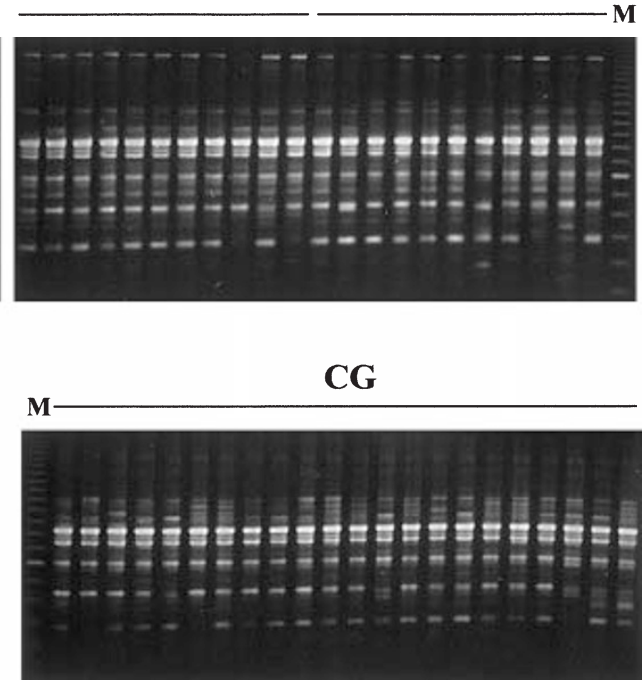

Fig. 2 Amplification products generated from 110 individuals of the five populations of Rosmarinus tomentosus using primer OPO-15. C-PC, population of Calahonda-Punta del Cerrón; CF-PG (I, II), subpopulations of Castell de Ferro-Punta Gorda; G (I, II), subpopulations of Guadalfeo; PM, population of Punta de la Mona; CG, population of Cerro Gordo. M, molecular size marker (100 bp ladder, Pharmacia). The $1500 \mathrm{bp}$ band is exclusive to population C-PC and the 2050 bp band is absent from populations $\mathrm{C}-\mathrm{PC}$ and $\mathrm{CG}$.

but close to it. Similarly, in the Guadalfeo population two individuals were not in the same cluster as the other individuals from the population. However, these two individuals were outside of the principal cluster of the remaining 108 individuals of $R$. tomentosus (Fig. 3). Also, clustering of individuals within subpopulations was observed in populations CF-PG and G. In population CF-PG, 64\% (7/11) of individuals of subpopulation I and $55 \%(6 / 11)$ of subpopulation II formed two clusters, respectively. Similarly, 75\% (9/12) of individuals of subpopulation G I and $50 \%(5 / 10)$ of G II formed two groups (Fig. 3).

The Mantel test revealed a significant cophenetic correlation $(r=0.76 ; P=0.001)$; thus, the dendrogram provides a good fit to the Dice's similarity matrix. The information from the cluster analysis was complemented by an analysis of variance of the coefficients of the similarity matrix calculated for each population. No significant differences were found between the mean similarity values for pairwise comparisons of individuals within the five populations.

\section{Genetic diversity estimates}

Genetic diversity measures within populations $\left(H_{\mathrm{o}}\right)$ for each primer and mean values with respect to all primers were calculated (Table 3). The highest genetic diversity values were obtained with primer OPO-1, in populations C-PC, G and CG, whilst the lowest were obtained with primers OPO-7 and OPO-8; the latter did not detect diversity in population CG. The highest and the lowest mean genetic diversity values were obtained in the populations G (2.915) and CF-PG (1.812), respectively.

The mean diversity within the five populations of $R$. tomentosus was $H_{\text {pop }}=2.335$, and the total diversity was $H_{\mathrm{sp}}=3.588$ (Table 3 ). The proportion of average diversity within populations $\left(H_{\mathrm{pop}} / H_{\mathrm{sp}}\right)$ was $65.9 \%$, and ranged between $52.6 \%$ (primer OPO-15) and 78.0\% (primer OPO-2). Of the total diversity, $34.1 \%$ was among the populations (Table 3); all primers detected more variability within than among populations.

\section{AMOVA partition}

Highly significant $(P<0.0005)$ genetic differences were detected in the analysis of molecular variance (AMOva) among zones, among populations (within zones and independently of zones), and among individuals (within populations and zones) (Table 4). Of the total molecular variance, $18.0 \%$ was attributable to zonal divergence, $18.5 \%$ to populational differences within zones, and $63.5 \%$ to individual differences within populations. When the total variance was partitioned without considering the zonal distribution of the populations, $34.1 \%$ was attributable to population divergence and $65.9 \%$ to individual differences within populations. Likewise, the partition considering only the zonal distribution of the individuals resulted in $29.2 \%$ of the total variance due to diversity among zones and $70.8 \%$ to individual differences within zones (Table 4). Bartlett's test for 
Fig. 3 Dendrogram of 110 individuals of Rosmarinus tomentosus from the five populations generated by UPGMA clustering analysis, using 126 RAPD markers. CF-PG, Castell de Ferro-Punta Gorda; C-PC, Calahonda-Punta del Cerrón; G, Guadalfeo; PM, Punta de la Mona; CG, Cerro Gordo. I \& II, subpopulations in the corresponding populations. The scale from 0.7 to 1.0 indicates genetic similarity calculated using the Dice's coefficient in NTSYS (Rohlf, 1992). Asterisks (*) indicate two individuals from Guadalfeo population that are outside of the all population clusters.

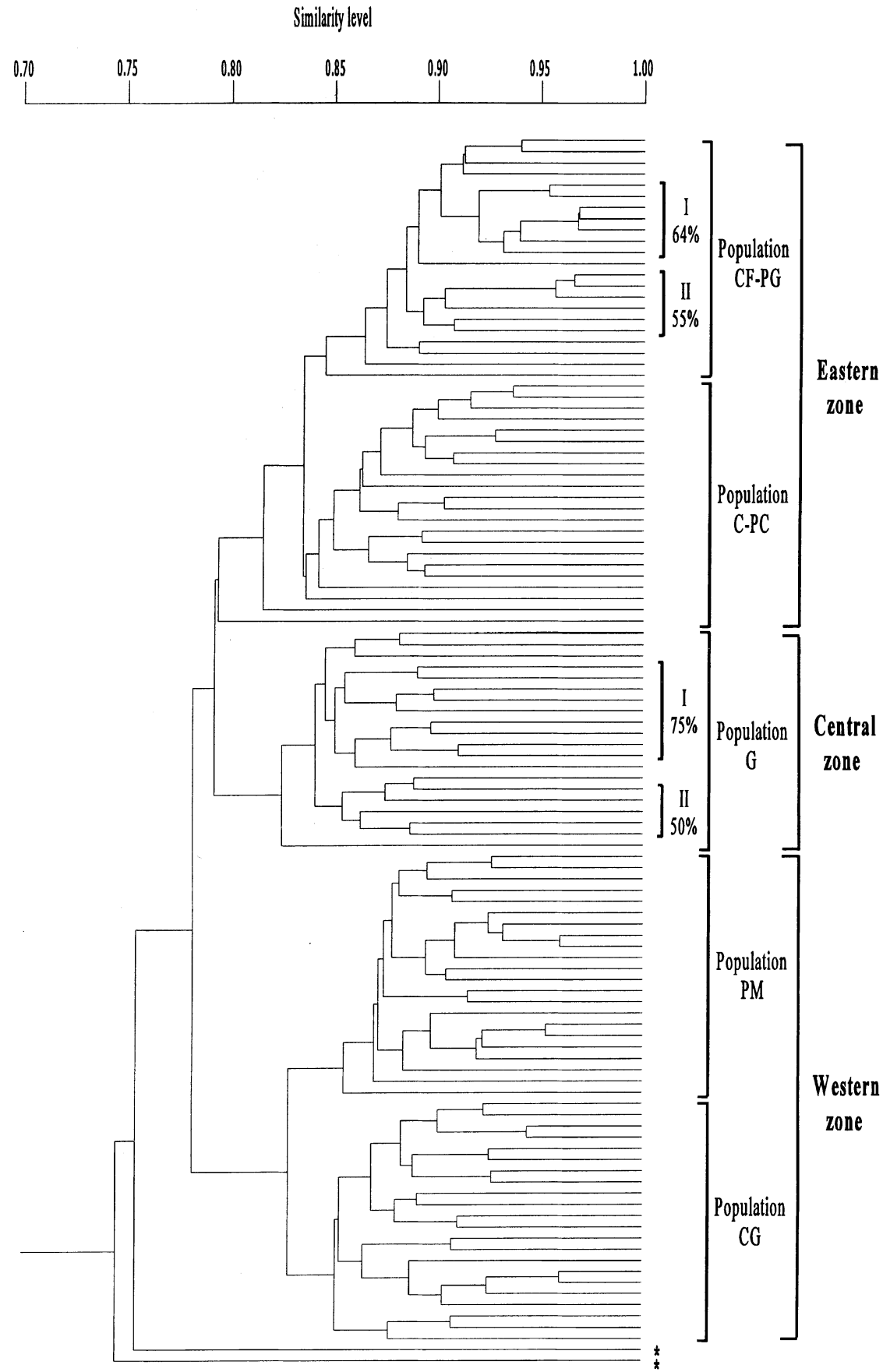

homogeneity of the RAPD variance among zones did not indicate significant differences $(P=0.092)$. On the other hand, the same test for homogeneity of variance for all pairwise population comparisons were highly significant $(P<0.0005)$.

Similar variance values were found among populations for eastern and western zones $(22.4 \%$ and $24.9 \%$, respectively) and among individuals within populations ( $77.6 \%$ and $75.1 \%$, respectively) (Table 4). Bartlett's test for homogeneity of the molecular variance indicated a greater significance between the two eastern populations (CF-PG and C-PC; $P<0.0005)$ compared to the two western populations (PM and CG; $P<0.05$ ).

Variance values among subpopulations of populations CF-PG and $\mathrm{G}$ were low (approx. 10\%) but genetic differences were highly significant $(P<0.0005)$ (Table 4$)$. Bartlett's test for homogeneity of variance indicated highly significant differences among subpopulations of 
Table 3 Estimates of genetic diversity parameters for the five populations of Rosmarinus tomentosus for eight RAPD primers. Populations are denoted as: CF-PG, Castell de Ferro-Punta Gorda; C-PC, Calahonda-Punta del Cerrón; G, Guadalfeo; PM, Punta de la Mona; CG, Cerro Gordo; $H_{\mathrm{pop}}$, average diversity within populations; $H_{\mathrm{sp}}$, total diversity; $H_{\mathrm{pop}} / H_{\mathrm{sp}}$, proportion of diversity within populations; $\left(H_{\mathrm{sp}}-\mathrm{H}_{\mathrm{pop}}\right) / H_{\mathrm{sp}}$, proportion of diversity among populations

\begin{tabular}{|c|c|c|c|c|c|c|c|c|c|}
\hline \multirow{2}{*}{$\begin{array}{l}\text { Primer } \\
\text { code }\end{array}$} & \multicolumn{5}{|c|}{$H_{\mathrm{o}}$} & \multirow[b]{2}{*}{$H_{\text {pop }}$} & \multirow[b]{2}{*}{$H_{\mathrm{sp}}$} & \multirow[b]{2}{*}{$H_{\text {pop }} / H_{\text {sp }}$} & \multirow[b]{2}{*}{$\left(H_{\mathrm{sp}}-H_{\mathrm{pop}}\right) / H_{\mathrm{sp}}$} \\
\hline & CF-PG & C-PC & G & PM & $\mathrm{CG}$ & & & & \\
\hline OPO-01 & 1.504 & 6.102 & 3.854 & 3.342 & 4.033 & 3.767 & 5.503 & 0.685 & 0.315 \\
\hline OPO-02 & 2.633 & 2.278 & 2.419 & 3.649 & 2.584 & 2.712 & 3.479 & 0.780 & 0.220 \\
\hline OPO-03 & 2.934 & 3.212 & 3.365 & 2.089 & 2.297 & 2.779 & 3.720 & 0.747 & 0.253 \\
\hline OPO-07 & 0.700 & 0.672 & 3.042 & 2.931 & 1.906 & 1.851 & 3.109 & 0.595 & 0.405 \\
\hline OPO-08 & 1.428 & 1.440 & 1.977 & 0.595 & 0 & 1.088 & 1.675 & 0.650 & 0.350 \\
\hline OPO-15 & 1.209 & 2.419 & 2.862 & 1.652 & 1.237 & 1.876 & 3.564 & 0.526 & 0.474 \\
\hline OPO-16 & 2.758 & 2.524 & 3.679 & 2.371 & 3.273 & 2.921 & 5.419 & 0.539 & 0.461 \\
\hline OPO-19 & 1.333 & 1.701 & 2.121 & 1.138 & 2.148 & 1.688 & 2.240 & 0.754 & 0.246 \\
\hline Means & 1.812 & 2.543 & 2.915 & 2.221 & 2.185 & 2.335 & 3.588 & 0.659 & 0.341 \\
\hline
\end{tabular}

Table 4 Analysis of molecular variance (AMOva) for 110 individuals of Rosmarinus tomentosus sampled from five populations studied, employing 126 RAPD markers. Nested analysis was carried out on all populations; on eastern and western zones (with two populations of each zone); on CF-PG and G populations (with two subpopulations each population). Statistics include degrees of freedom (d.f.), mean squared deviations (MSDs), variance component estimates, the probability $(P)$ of obtaining a more extreme component estimate by chance alone (after 2000 permutations), and the percentage of the total variance contributed by each component

\begin{tabular}{|c|c|c|c|c|c|}
\hline Source of variation & d.f. & MSD & $\begin{array}{l}\text { Variance } \\
\text { component }\end{array}$ & $P$-value & $\begin{array}{l}\% \text { total } \\
\text { variance }\end{array}$ \\
\hline \multicolumn{6}{|l|}{ Nested analysis } \\
\hline Among zones & 2 & 119.06 & 1.94 & $<0.0005$ & 17.98 \\
\hline Among populations within zones & 2 & 50.78 & 1.99 & $<0.0005$ & 18.52 \\
\hline Among individuals within populations & 105 & 6.85 & 6.85 & $<0.0005$ & 63.50 \\
\hline \multicolumn{6}{|l|}{ Analysis among populations } \\
\hline Among populations & 4 & 84.92 & 3.55 & $<0.0005$ & 34.13 \\
\hline Among individuals within populations & 105 & 6.85 & 6.85 & & 65.87 \\
\hline \multicolumn{6}{|l|}{ Analysis among zones } \\
\hline Among zones & 2 & 119.06 & 3.16 & & 29.21 \\
\hline Among individuals within zones & 107 & 7.67 & 7.67 & & 70.79 \\
\hline \multicolumn{6}{|l|}{ Eastern zone only } \\
\hline Among populations & 1 & 48.11 & 1.89 & $<0.0005$ & 22.43 \\
\hline Among individuals within populations & 42 & 6.54 & 6.54 & & 77.57 \\
\hline \multicolumn{6}{|l|}{ Western zone only } \\
\hline Among populations & 1 & 53.46 & 2.14 & $<0.0005$ & 24.89 \\
\hline Among individuals within populations & 42 & 6.45 & 6.45 & & 75.11 \\
\hline \multicolumn{6}{|l|}{ CF-PG population only } \\
\hline Among subpopulations & 1 & 11.70 & 0.58 & $<0.0005$ & 9.73 \\
\hline Among individuals within subpopulations & 20 & 5.35 & 5.35 & & 90.27 \\
\hline \multicolumn{6}{|l|}{ G population only } \\
\hline Among subpopulations & 1 & 16.69 & 0.81 & $<0.0005$ & 9.35 \\
\hline Among individuals within subpopulations & 20 & 7.86 & 7.86 & & 90.65 \\
\hline
\end{tabular}


Table 5 Geographical distances $(\mathrm{km})$ (above diagonal) and genetic distances $\left(\mathrm{Phi}_{\mathrm{st}}\right.$ values $\times 100$ ) (below diagonal) between populations of Rosmarinus tomentosus. Populations are denoted: CF-PG, Castell de Ferro-Punta Gorda; C-PC, Calahonda-Punta del Cerrón; G, Guadalfeo; PM, Punta de la Mona; CG, Cerro Gordo

\begin{tabular}{lccccc}
\hline & CF-PG & C-PC & G & PM & CG \\
\hline CF-PG & - & 2.00 & 16.80 & 31.50 & 36.00 \\
C-PC & 22.43 & - & 15.50 & 29.50 & 34.30 \\
G & 30.60 & 28.90 & - & 18.50 & 22.70 \\
PM & 45.27 & 41.60 & 31.80 & - & 5.00 \\
CG & 42.72 & 36.62 & 31.24 & 24.89 & - \\
\hline
\end{tabular}

population $\mathrm{G}(P<0.0005)$, although the test was not significant in population CF-PG $(P=0.034)$.

Genetic distances among populations of $R$. tomentosus obtained from AMOva ( $\mathrm{Phi}_{\mathrm{st}}$ values between pairs of populations) revealed a larger separation among populations from different zones than a pair of populations located in the same zone (Table 5). All distances between pairs of populations were significantly different from zero. The Mantel matrix correspondence test indicated a significant correlation between the matrix of genetic distances among populations with the corresponding matrix of geographical distances $(r=0.926 ; P=0.038)$.

\section{Discussion}

Analyses of the RAPD markers using different approaches (cluster analysis, Shannon's diversity measure and AMOVA) demonstrated similar interpretations of the genetic structure of populations of $R$. tomentosus. The present study revealed a high level of polymorphism $(86 \%)$ in the five populations of $R$. tomentosus; considering each population separately, this value ranged between $54 \%$ and $72 \%$. The percentage of polymorphic bands within populations of $R$. tomentosus is relevant for a rare endemic species, and is comparatively higher than in the other allogamous rare endemic species, such as Allium aaseae (40-63\%; Smith \& Pham, 1996) and Erodium paularense (44-51\%; Martín et al., 1997). Populations C-PC and G showed the highest number of polymorphic markers (about 70\%), and, hence, the highest estimates of genetic diversity (Table 3). The dendrogram (Fig. 3) shows that two of the 22 analysed individuals from each of these two populations were displaced from their corresponding population clusters, and may be one of the reasons for these populations showing a greater diversity. The separation of the two variant individuals in the Guadalfeo valley population (G) from the principal cluster could be the result of hybridization between $R$. tomentosus and $R$. officinalis
(Rosúa, 1981, 1986), which is especially frequent in this interior central zone.

The AMOva analysis shows that $18.0 \%$ of the total variance is attributable to zonal differences, and indicates significant genetic differentiation among zones. However, Bartlett's test point out no significant differences for the homogeneity of the variance among zones; hence, the genetic divergence was similar in the three zones. The results of the partition of variation among populations and among individuals within populations were identical when comparing Shannon's information measure and AMOva (Tables 3 and 4). A close association exists between breeding system and the distribution of genetic diversity (Schoen \& Brown, 1991; Hamrick \& Godt, 1996). Inbreeding species are generally characterized by high levels of genetic differentiation among populations, whilst outbreeding plants tend to retain considerable variability within populations (Hamrick, 1990; Hamrick \& Godt, 1996). Genetic differentiation estimates among populations for outbreeding species when RAPD markers have been analysed using Shannon's index ranged between $15 \%$ and $38 \%$, and using the analysis of molecular variance this value was usually $<40 \%$. For inbred species, interpopulation genetic variation was usually $>50 \%$ (reviewed in Bussell, 1999). The genetic variation among populations of $R$. tomentosus $(34.1 \%)$ is towards the higher limit and is in agreement with the outbreeding nature of the species. There are other outbreeding plant species that present similar values, e.g. Alkanna orientalis (32-38\%; Wolff et al., 1997), Cedrela odorata (35-37\%; Gillies et al., 1997), and slightly higher values, as in the other endangered plant, Caesalpinia echinata (41\%; Cardoso et al., 1998).

The analysis of molecular variance shows highly significant differences among populations, and Bartlett's test also indicates highly significant heterogeneity of the variance among populations. Also, all $\mathrm{Phi}_{\mathrm{st}}$ distances between pairs of $R$. tomentosus populations are significantly different from zero; thus, the five populations may be considered genetically to be significantly different from each other. These results indicate high genetic isolation among populations. However, a significant loss of diversity through genetic drift has not been detected in the present study, probably because the size of the populations is not critically low as shown by Ellstrand \& Elam (1993). The significant correlation between the matrix of genetic distances ( $\mathrm{Phi}_{\mathrm{st}}$ values) and the matrix of geographical distances among populations $(r=0.926$; $P=0.038)$ indicates that geographical isolation is an important factor influencing the genetic structure of $R$. tomentosus populations. Similar observations were made in Caesalpina echinata, which also has fragmented populations (Cardoso et al., 1998). Both the eastern and 
western regions show similar levels of variation among populations (about 25\%) and the genetic differentiation was highly significant. Moreover, Bartlett's test for the homogeneity of variance indicates a significantly greater genetic isolation between the two eastern populations (CF-PG and C-PC; $P<0.0005$ ) than between the two western populations (PM and CG; $P<0.05$ ). This significantly higher isolation between the two eastern populations may be related to the increase of the climatic aridity from west to east in this coastal region, which may consequently slow pollinator activity. The partitioning of variance among subpopulations of CF-PG and G (approx. 10\%) are significant. Nevertheless, Bartlett's test for homogeneity of variance indicates a significant isolation between the two subpopulations of $\mathrm{G}$, and not for the two subpopulations of CF-PG. In other words, it appears that a separation of $200 \mathrm{~m}$ (in subpopulations of CF-PG) between groups of $R$. tomentosus individuals does not impede gene flow, although a separation of about $500 \mathrm{~m}$ (in subpopulations of $\mathrm{G}$ ) produces significant isolation.

The UPGMA dendrogram (Fig. 3) and the AmovA analysis (Table 4) show a clear genetic differentiation among zones, among populations (within zones and independently of zones), and a considerable divergence between subpopulations. The movement of genes among populations has a significant influence on the distribution of genetic variation. Species with restricted gene flow should exhibit more genetic differentiation than species with widely dispersed pollen and seeds (Hamrick, 1990). The strong genetic differentiation in $R$. tomentosus would suggest that gene flow among different groups of individuals is very low. Genetic differentiation among populations attributed to a limited or absent interpopulation gene flow has been reported for other endemic or endangered plant species (Brauner et al., 1992; Travis et al., 1996; Martín et al., 1997; Cardoso et al., 1998). Although the majority of Labiatae species favour outcrossing, their lack of self-incompatibility forces them to activate mechanisms that help them avoid excessive self-pollination (Owens \& Ubera-Jiménez, 1992). $R$. tomentosus staggers its flowering throughout the year, resulting in just a few open flowers on any given plant at one time (Hernández Bermejo \& Clemente Muñoz, 1994). The hymenopteran visitors therefore have to go from plant to plant searching for the few $R$. tomentosus flowers that are open; this is especially true in spring and summer. Thus, it is possible that staggering flowering may slightly increase gene flow in $R$. tomentosus, but it is still quite low as indicated by this analysis using RAPD markers. Moreover, $R$. tomentosus is a species with mainly gravity-dispersed seeds, and most seedlings establish close to the mother plant (J.E. Hernández Bermejo, pers. obs.). The limited seed dispersal also contributes to reduced gene flow, increasing genetic variation among different groups of individuals (Hamrick, 1990).

In short, the limited gene flow among different populations and subpopulations of $R$. tomentosus, together with the geographical separation, may explain the high level of isolation and the high genetic differentiation observed among populations and even among subpopulations from the three zones studied.

The use of RAPD markers to characterize and determine the genetic structure of the populations has proved to be a useful tool in the study of Rosmarinus tomentosus. Considering the fragmented distribution of this endemic and endangered species, and the high genetic differentiation among populations as detected in the present study, we suggest that in situ conservation measures should include all the existing clusters of individuals (from subpopulation level to zonal level). The ex situ conservation may be carried out by collecting seeds from each of the zones, populations, and include different subpopulations for long-term storage in germplasm banks.

\section{Acknowledgements}

This work was supported by the Spanish Government, CICYT project no. AMB96-1021-C02-01. We personally thank our colleagues $\mathrm{M}$. Clemente-Muñoz, A. Escudero, A. Lora, J.M. Iriondo, J. Prados and J.L. Vivero for their collaboration with the field work in the $R$. tomentosus habitat.

\section{References}

BRAUNER, S., CRAWFORD, D. J. AND STUESSY, T. F. 1992. Ribosomal DNA and RAPD variation in the rare plant family Lactoridaceae. Am. J. Bot., 79, 1436-1439.

BUSSELL, J. D. 1999. The distribution of random amplified polymorphic DNA (RAPD) diversity amongst populations of Isotoma petraea (Lobeliaceae). Mol. Ecol., 8, 775-789.

CARdoso, M. A., PRovan, J., POWELl, W., FERREIRAS, P. C. G. AND DE OLIVEIRA, D. E. 1998. High genetic differentiation among remnant populations of the endangered Caesalpinia echinata Lam. (Leguminosae-Caesalpinioideae). Mol. Ecol., 7, 601-608.

Clark, A. G. AND LANigAN, C. M. S. 1993. Prospects for estimating nucleotide divergence with RAPDs. Mol. Biol. Evol., 10, 1096-1111.

DICE, L. R. 1945. Measures of the amount of ecologic association between species. Ecology, 26, 297-302.

Ellstrand, N. C. AND ElAM, D. R. 1993. Population genetic consequences of small population size: implications for plant conservation. Ann. Rev. Ecol. Syst., 24, 217-242.

EXCOFFIER, N. C., SMOUSE, P. E. AND QUATTRO, J. M. 1992. Analysis of molecular variance inferred from metric 
distances among DNA haplotypes: application to human mitochondrial DNA restriction data. Genetics, 131, 479491.

Gillies, A. C. M., CORNELIUS, J. P., NEWTON, A. C., NAVARro, C., HERNÁNDEZ. M. AND WILSON, J. 1997. Genetic variation in Costa Rican populations of the tropical timber species Cedrela odorata L., assessed using RAPDs. Mol. Ecol., 6, 1133-1145.

HADRYS, H., BALICK, M. AND SCHIERWATER, B. 1992. Application of random amplified polymorphic DNA (RAPD) in molecular ecology. Mol. Ecol., 1, 55-63.

HAMRICK, J. L. 1990. Isozymes and the analysis of genetic structure in plant populations. In: Soltis, D. E. and Soltis, P. S. (eds) Isozymes in Plant Biology, pp. 87-105. Chapman \& Hall, London.

HAMRICK, J. L. AND GODT, M. J. W. 1996. Effects of the life history traits on genetic diversity in plant species. Phil. Trans. R. Soc. B, 351, 1291-1298.

HERNÁNDEZ BERMEJO, J. E. AND CLEMENTE MUÑOZ, M. 1994. Protección de la Flora En Andalucía. Consejería de Cultura y Medio Ambiente, Junta de Andalucía, Seville.

HUFF, D. R., PEAKAll, R. AND SMOUSE, P. E. 1993. RAPD variation within and among natural populations of outcrossing buffalograss [Buchloë dactyloides (Nutt.) Engelm.]. Theor. Appl. Genet., 86, 927-934.

IUCN 1994. IUCN Red List Categories. IUCN, Gland, Switzerland.

KING, L. M. AND SCHAAL, B. A. 1989. Ribosomal DNA variation and distribution in Rudbeckia missouriensis. Evolution, 43, 1117-1119.

LYNCH, M. AND MilligAN, B. G. 1994. Analysis of population genetic structure with RAPD markers. Mol. Ecol., 3, 91-99.

MAIRE, R. 1940. Sur un Romarin nouveau de l'Espagne meridionale. Bull. Soc. Hist. Nat. Afr. Nord, 31, 79.

MAKI, M. AND HORIE, S. 1999. Random amplified polymorphic DNA (RAPD) markers reveal less genetic variation in the endangered plant Cerastium fischerianum var. molle than in the widespread conspecific $C$. fischerianum var. fischerianum (Caryophyllaceae). Mol. Ecol., 8, 145-150.

MANTEL, N. 1967. The detection of disease clustering and a generalized regression approach. Cancer Res., 27, 209-220.

MARTÍN, C., GONZÁLEZ-BENITO, M. E. AND IRIONDO, J. M. 1997. Genetic diversity within and among populations of a threatened species: Erodium paularense Fern. Gonz. \& Izco. Mol. Ecol., 6, 813-820.

OWENS, S. J. AND UBERA-JIMÉNEZ, J. L. 1992. Breeding systems in Labiatae. In: Harley, R. M. and Reynolds, T. (eds) Advances in Labiatae Science, pp. 257-280. Royal Botanic Gardens, Kew.

ROHLF, F. J. 1992. NTSYS-PC: Numerical taxonomy and multivariate analysis system, v. 1.60. Exeter Software, New York.

ROSSETTO, M., WEAVER, P. K. AND DIXON, K. W. 1995. Use of RAPD analysis in devising conservation strategies for the rare and endangered Grevillea scapigera (Proteaceae). Mol. Ecol., 4, 321-329.

RosúA, J. L. 1981. El complejo Rosmarinus eriocalyx-tomentosus en la Península Ibérica. Anales Jard. Bot. Madrid, 37, 587-595.

RosúA, J. L. 1986. Contribución al estudio del género Rosmarinus L. en el Mediterráneo occidental. Lagascalia, 14, 179-187.

SCHOEN, D. J. AND BROWN, A. H. D. 1991. Intraspecific variation in population gene diversity and effective population size correlates with the mating system in plants. Proc. Natl. Acad. Sci. U.S.A., 88, 4494-4497.

SMITH, J. F. AND PHAM, T. V. 1996. Genetic diversity of the narrow endemic Allium aaseae (Alliaceae). Am. J. Bot., 83, 717-726.

TORRES, A. M., WEEDEN, N. F. AND MARTíN, A. 1993. Linkage among isozyme, RFLP and RAPD markers in Vicia faba. Theor. Appl. Genet., 85, 937-945.

TRAVIS, S. E., MASCHINSKI, J. AND KEIM, P. 1996. An analysis of genetic variation in Astragalus cremnophylax var. cremnophylax, a critically endangered plant, using AFLP markers. Mol. Ecol., 5, 735-745.

WEISING, K., NYBOM, H., WOLFF, K. AND MEYER, w. 1995. DNA Fingerprinting in Plants and Fungi. CRC Press, Boca Raton, FL.

WILLIAMS, J. G. K., KUBELIK, A. R., LIVAK, K. J., RAFALSKI, J. A. AND TINGEY, S. v. 1990. DNA polymorphism amplified by arbitrary primers are useful as genetic markers. Nucl. Acids Res., 18, 6531-6535.

WOlfF, K., El-AKKAD, S. AND ABbotT, R. J. 1997. Population substructure in Alkanna orientalis (Boraginaceae) in the Sinai Desert, in relation to its pollinator behaviour. Mol. Ecol., 6, 365-372. 